\title{
Punica granatum (Pomegranate) activity in health promotion and cancer prevention
}

\author{
Shahindokht Bassiri-Jahromi \\ Medical Mycology Department, Pasteur Institute of Iran, Thran, Iran
}

\begin{abstract}
Cancer has become one of the most fatal diseases in most countries. In spite of the medical care developing, cancer still remains a significant problem. The majority of the cancers are resistant to treatment. Thus, the research for novel, more efficient and less side effect treatment methods continues. Pomegranate contains strong antioxidant activity, with potential health interests. Research concern in pomegranate is increasing because of their anticancer potential due to possess rich in polyphenols. We highlight the pomegranate potential health benefits and mechanism of cancer progression inhibition. Pomegranate has indicated antiproliferative, anti-metastatic and anti-invasive effects on different cancer cell line in vitro, in vivo and clinical trial. The aim of this review is to evaluate functional properties and the medical benifits of pomegranate against various cancer diseases. In addition, pomegranate properties in in vitro and in vivo experimental human and animal clinical trials and its future use are explored. The available data suggest that Punica granatum (pomegranate) might be used in the control and potential therapeutic for some disease conditions and benefits human health status. This review summarizes in vitro, in vivo and clinical trial studies highlighting the pomegranate role in prevent and treatment of breast, prostate, lung, colon, skin and hepatocellular cell cancers.
\end{abstract}

Correspondence: Shahindokht Bassiri-Jahromi, Medical Mycology Department, Pasteur Institute of Iran, P.O. Box: 1316943551 Thran, Iran.

Tel.: +98.21.6695331.20 - Fax: +98.21.66465132.

E-mail: basiri@pasteur.ac.ir

Key words: Punica granatum (pomegranate); natural product; treatment; cancer; prevention and control.

Acknowledgments: the authors thank the Pasteur Institute of Iran Council of Research for financial support and scholarships (2 may 2012 /TP -9003).

Received for publication: 29 November 2018.

Accepted for publication: 25 January 2018.

This work is licensed under a Creative Commons Attribution NonCommercial 4.0 License (CC BY-NC 4.0).

CC Copyright S. Bassiri-Jahromi, 2018

Licensee PAGEPress, Italy

Oncology Reviews 2018; 12:345

doi:10.4081/oncol.2018.345

\section{Introduction}

Pomegranates (Punica granatum L.) have prominent medical history, and possess remarkable medicinal properties. ${ }^{1}$ Pomegranate is native in Asian countries including Iran to Northern India. It has been cultivated and naturalized over the whole Mediterranean region since ancient times. ${ }^{2}$ Pomegranate has been the subject of current attractive as a medicinal agent with wide variety therapeutic indications.

Studies have demonstrated that pomegranates may use as natural remedy to chemical treatment due to their capability against a wide range of pathogens. Approximately every part of the pomegranate, including the fruit juice, peel, arils, flowers, and bark has been tested for antimicrobial activities. There are wide ranges of phytochemical properties have demonstrated antimicrobial activities in pomegranate. Ellagic acid and hydrolysable tannins, such as punicalagin, have the most activities. ${ }^{3}$

The use of the pomegranate juice, peel and oil has been indicated that pomegranate have anticancer activities, including interference with tumor cell proliferation, cell cycle, invasion and angiogenesis. These may be related to anti-inflammatory effects of pomegranate. The phytochemistry and pharmacological actions of pomegranate properties indicate a wide variety of clinical usage for the cancer prevention and treatment, also other diseases where chronic inflammation is reliable to play a main etiologic role. ${ }^{4}$

In the past decade, numerous studies on pomegranate constituents have been published.

The results suggest that pomegranate components have antioxidant, anti-carcinogenic and anti-inflammatory components, which is effective on prevention and treatment of cancer and other chronic and infection diseases. ${ }^{5-7}$

The aim of this systematic review was to summarize the presnt data on the medical-activity of pomegranate products from in vitro and in vivo experiments animal and human clinical trials in prevention and treatment of breast, lung, prostate, colon, skin and hepatocellular cell cancers.

\section{Punica granatum L. compound}

Pomegranate is an important source of bioactive properties and has been shown anticancer activities. Pomegranate contains strong antioxidant activity and has a high source of ellagitannins, anthocyanins, and hydrolysable tannins. ${ }^{8}$

The most components of the pomegranatesare tannin and polyphenolics. ${ }^{9}$ Phytochemical analyses indicated that pomegranate peels possess active inhibitors, including phenolics and flavonoids. ${ }^{10}$

Pomegranate peel has ellagitannins, ellagic acid, gallic acid, ${ }^{11}$ hydroxybenzoic acids such as ellagic acid, gallagic acid, and ellagic acid glycosides. ${ }^{12}$ Punicalagin is the major bioactive com- 
ponent of pomegranate peel. ${ }^{13}$ Anthocyanidins are mainly contained cyanidin, pelargonidin and delphinidin ${ }^{14}$ and flavonoids such as kaempferol, luteolin, and quercetin. ${ }^{15}$

Ozbay et al. ${ }^{16}$ reported that delphinidin presents growth inhibitory activity in breast cancer cells of different molecular subtypes, but elevate potential drug antagonism when used in combination with existing targeted therapies in HER2-overexpressing breast cancer.

Murthy et al. ${ }^{17}$ quantified methanolic extract of pomegranate peel by used chromatographic method (i.e. HPLC) and reported gallic acid (34.03\%) and catechin (3.31\%) presented.

Middha et al. ${ }^{18}$ revealed antioxidant activity, polyphenolic, nutritive content, and phenolic specifications of methanol and aqueous extracts of $P$. granatum peel extract.

Botanical antioxidants usages have gained considerable attention as photochemopreventive agents. ${ }^{19}$

Investigation by HPLC method on the phenolic specification of the methanolic extracts showed about 5 different flavonoids, phenolic acids, and their derivatives including quercetin rutin, gallic acid, ellagic acid, and punicalagin as a major ellagitannin have been specified.

In study by Akbarpour et al. ${ }^{20}$ were analyzed physical and chemical properties of twelve pomegranate ( $P$. granatum L.) cultivars from different regions of Iran. Results of HPLC showed, ellagic acid content of juice and peel ranged were between 1-2.38 $\mathrm{mg} / 100 \mathrm{~mL}$ and $10-50.00 \mathrm{mg} / 100 \mathrm{~g}$, respectively. Total antioxidant activity in peel and juice measured by FRAP assay with a range of 225.17-705.50 (mmol/100 g) and 157.33-419.33 (mmol/100 mL), respectively.

\section{Summary of evidence on prevention effectiveness}

Pomegranate has been used to therapeutic the several diseases among various cultures and civilizations. The potential therapeutic of $P$. granatum peel covering an extensive range,

including cancer treatment and prevention by laboratory and clinical evidence, ${ }^{21,22}$ antimicrobial, ${ }^{23,24}$ antifungal by in vitro and in vivo evidence, ${ }^{25-27}$ and antiviral, ${ }^{28}$ It has also been effective in treatment of cardiovascular disease in Wistar rats, ${ }^{29}$ diabetes in hyperglycemic rats, ${ }^{30}$ denture stomatitis and mouth lesions in cultured cells ${ }^{31}$ and in clinical trial, ${ }^{32}$ and protective activity from ultraviolet radiation in ultraviolet-irradiated human skin fibroblasts, ${ }^{33}$ and other potential usage include Alzheimer's disease in Transgenic Mouse Model, ${ }^{34}$ cerebral ischemia ischemia in rat model and in human, ${ }^{35,36}$ arthritis in human chondrocytes, ${ }^{37}$ skin lesions in rats, ${ }^{38}$ obesity and lipid lowering effect in rats, ${ }^{39}$ malaria by in vitro, ${ }^{40}$ prostate cancer in clinical trial, ${ }^{41,42}$ atherosclerosis in mice, ${ }^{43}$ hypertension in Wistar rats. ${ }^{44}$ Many researchers have focused on the biological activity of pomegranate peels. They found that the poly phenols have been demonstrated to have promoting health and preventive disease activity. The free radicals are demonstrated to stimulate and aggravate many diseases like arthritis, cancer, Alzheimer's disease, diabetic complications and Parkinson's disease. ${ }^{45}$ These results indicated that pomegranate peel could be used as a possible source of natural antioxidant agents and tyrosinase inhibitors.

\section{Antioxidant activity}

Pomegranate peel extracts contains a lots of phytochemicals and considerable antioxidant activity, to be due to ellagic acid activity, which is the main pomegranate polyphenol. ${ }^{46}$
Singh et al. ${ }^{47}$ explained the first report on antioxidant pomegranate peel extract property. The pomegranate peel extract antioxidant activity is 10 times higher than the pulp extract. ${ }^{48}$ Peel extract ability in cleaning hydroxyl and superoxide anion radical was also very high. ${ }^{49}$ So pomegranate extracts are offered as two functional agents combining aldose reductase repressive activity with antioxidant actions.

Polyphenolic compounds source is in pomegranate seed oil; peel and juice have anti-oxidant action and inhibit pro-inflammatory enzymes including the cyclooxygenases and lipoxygenases. ${ }^{47,50-53}$

Studies in rats with $\mathrm{CCl}_{4}$-induced liver damage showed pomegranate peel pretreatment evaluate the free radical inhibitory effect of superoxide dismutase, the hepatic enzymes catalase, and peroxidase resulted in 54\% lowering of lipid peroxidation values in compare to control group confirming the antioxidant cantent of the pomegranate peel. ${ }^{54}$ The other study demonstrated that rats feeding with pomegranate peel enabled protective activity against carbon tetra chloride $\left(\mathrm{CCl}_{4}\right)$ toxicity. ${ }^{55}$ Pomegranate pulp extract has a wide inhibitory activity on matrix metalloproteinaises (MMPs) expression and IL- $1 \beta$ induced tissue destruction. ${ }^{56}$

\section{Anti-cancer activity}

Due to current chemotherapeutic regimens problems, there is a shifting to finding natural compounds currently that may be useful in preventing and to treat cancers.

Pomegranate has anti-proliferative effect and anti-cancer activities against prostate, colon, oral, and breast-cancer cell lines. Pomegranate identified in preventing and therapeutic activity of inflammation and cancer, and it has an efficient result against oxidative damage in diabetic rats. ${ }^{1,21,23,41,42,46,57}$ Pomegranate extract have indicated promising anti-tumor activities in various organs. Pomegranate contain polyphenols that they showed anticarcinogenic activities by in vitro and in vivo investigations. ${ }^{1,9,35,58-}$ 61 Pomegranate extract induced apoptosis and inhibited proliferation in cancer cells, also pomegranate juice induced significant apoptosis in lymphoid and myeloid leukemia cell lines, associated with cell cycle arrest. ${ }^{60}$ Study by Adhami et al. ${ }^{21}$ has indicated that pomegranate extracts prevented the breast, prostate, colon and lung cancer cells growth in in vitro. Pomegranate extract have capability to inhibited lung, skin, colon and prostate tumors growth in preclinical animal studies. ${ }^{21}$ Pomegranate juice showed significant prolongation of prostate specific antigen doubling time in patients with prostate cancer in an initial phase II clinical trial. In experimental studies pomegranate seed oil has been demonstrated proliferation prevention of various tumor cell types ${ }^{61-64}$ and skin carcinogenesis reduction in mice ${ }^{65}$ and carcinogenesis in a mouse mammary organ culture model. ${ }^{66}$ The pomegranate juice activity indicates of synergistic or additive effects from the other phytochemicals present in pomegranate juice. ${ }^{67}$

Pomegranate peel extracts have been illustrated to delay proliferation of cells in different cancer cell lines. ${ }^{63,68,69}$ Anti-carcinogenic properties of different combinations of the phytochemicals in pomegranate were studied by Adams et al. ${ }^{70}$

Investigation by Tang et al. showed that punicalagin have chemo preventive and chemotherapeutic activities against cervical cancer in humans through inhibition of the $\beta$-catenin signaling pathway. ${ }^{13}$ Purified ellagic acid was compared with its precursor punicalagin, and the total pomegranate juice tannins. All of them reduced the viable cell number of human oral and colon tumor cells; pomegranate juice had more action and has the most effective antioxidant sample tested. 
Naiki et al..$^{71}$ reported that pomegranate juice and ellagic acid are potential chemo preventive agents for prostate cancer, and Ellagic acid may be the active component of pomegranate juice that perform these anti-cancer effects.

Pomegranate juice also stimulated apoptosis when concentrations of isolated tannins that were equalized to amounts found in pomegranate juice had no effect. ${ }^{72}$ The juice also contains phytochemicals such as anthocyanins and flavonoids, which possess antioxidant and anti-proliferative activity. ${ }^{73}$ The synergistic action of the pomegranate constituents appears to be superior to that of single constituents. ${ }^{64,73}$

\section{Anti-breast cancer}

Pomegranate extract indicated anti-inflammatory and cytotoxic activities as in vitro and in vivo in breast cancer cells. The anticancer potential of pomegranate extract in breast cancer cells is due to targeting microRNAs155 and 27a partly. Pathways play an importantrole in the proliferation and inflammation phenotype exhibited by these cell lines. Pomegranate seed oil has been demonstrated to prevent proliferation of different tumor cell types in experimental studies, ${ }^{61,74}$ and reduce mammary carcinogenesis in the mouse mammary organ. ${ }^{66}$ Pomegranate extracts inhibit the growth of MCF-7 breast cancer cells through induction of apoptosis. ${ }^{75}$ Mehta ${ }^{66}$ showed increased breast cancer preventive potential for the purified compound and pomegranate seed oil, more than pomegranate fermented juice polyphenols. Pomegranates have the ability to suppress expansion of new blood vessels. Development of angiogenesis is necessary to supply oxygen and nutrients for growth and metastasis of tumor.

The investigation by Kim et al. ${ }^{61}$ indicated preventive effect of pomegranate components against different breast cancer, and it suggests a possible pomegranate role in suppress and treat of cancer.

Study by Shirode et al. illustrated that encapsulation of pomegranate polyphenols enhances their bio efficacy inhibited cancer cell growth in MCF-7 and Hs578T breast cancer cells. ${ }^{74}$

\section{Anti-prostate cancer}

Pomegranate activity has been assessed on prostate cancer in the cell culture, animal models. ${ }^{41,62,64}$ Also patients with prostate cancer in an initial phase II clinical trial, pomegranate juice has shown considerable prolongation doubling time of prostate specific antigen. ${ }^{21}$

Preclinical animal investigations showed the oral pomegranate extract administration inhibited growth of prostate tumors. ${ }^{21}$ The first pomegranate juice clinical trial in patients with prostate cancer reported by Pantuck et al. ${ }^{76}$ indicated that the statistically remarkable prolongation of prostate-specific antigen (PSA) doubling time.

These activities were observed to be mediated by changes in cell cycle distribution and induction of apoptosis. ${ }^{74}$

\section{Anti-lung cancer}

The effects of pomegranate extract on lung tumor genesis were investigated both in vitro and in vivo by authors. ${ }^{76-78}$ These investigations showed that pomegranate extract could be useful chemo preventive and chemo-therapeutic agent against human lung can- cer. Li et al. ${ }^{79}$ have been shown that pomegranate leaves extract suppressed cell proliferation in non-small cell lung carcinoma cell line in a dose and time-dependent manner. Pomegranate leaves extract affected H1299 cell survival by arresting cell cycle progression in $\mathrm{G} 2 / \mathrm{M}$ phase. These researchers suggested that pomegranate leaves extract could be an effective and safe chemotherapeutic agent in non-small cell lung carcinoma treatment by inhibiting proliferation, inducing apoptosis, cell cycle arrest and impairing cell migration and invasion. Pomegranate extract able to suppress pro survival pathways in human A549 lung carcinoma cells and tumor growth in the nude mice. ${ }^{77}$

Khan et al. showed that pomegranate extract remarkably inhibits lung carcinogenesis in the mice model and able investigate as a chemo preventive agent for human lung cancer. ${ }^{80}$

So, pomegranate extract can be a benefit chemo preventive and chemotherapeutic factor versus human lung cancer.

\section{Anti-colon cancer}

Inflammation has the main role in the growth of colon cancer, and different anti-inflammatory agents have indicated promise for prevention of colon cancer. Pomegranate seed oil exhibits chemo preventive activity against experimental colon carcinogenesis. Adams et $a l . .^{70}$ have reported the anti-inflammatory action of pomegranate juice on the signaling proteins in HT-29 human colon cancer cell line.

Administration of pomegranate seed oil enhanced peroxisome proliferator-activated receptor (PPAR) gamma protein expression in the non-tumor mucosa and remarkably prevented the incidence of colonic adeno-carcinomas. ${ }^{81}$

Investigation by Larrosa et al. ${ }^{82}$ in the colitis in the rat model and the effect of colon inflammation on phenolic metabolism, showed that Anti-inflammatory properties of a pomegranate extract and its metabolite urolithin-A could be the most active antiinflammatory compound derived from pomegranate ingestion in healthy subjects, whereas in colon inflammation, the effects could be due to the non-metabolized ellagitannin-related fraction.

Results obtained by Kohno et al. ${ }^{83}$ indicated that pomegranate seed oil can inhibits azoxymethane induced colon carcinogenesis, and the suppression is related partly with the increased content of conjugated linoleic acid in the colon and liver and elevated expression of PPAR gamma protein in the mucosa of colon.

\section{Anti-skin cancer}

Pomegranate extract is a high source of ellagitannins, anthocyanins, and tannins and possesses powerful antioxidant acting. Tannins compound, have remarkable activity in cancer prevention. ${ }^{84}$ Tannin stimulated release of an interleukin 1 (IL-1) and IL-1 beta from the cells in the mice and humans macrophages in in vitro. These results suggest that tannins applies its antitumor effect via activation of macrophages. ${ }^{85}$

There are some observations showing evidence that pomegranate pulp extract contains anti-skin tumor promoting activity in CD1 mouse by preventing prevalent also new biomarkers of tetra decanoyl phorbol 13-acetate (TPA)-induced tumor promotion. ${ }^{86-90}$

Pomegranate seed oil has been exhibited in experimental studies to inhibit proliferation of various tumor cell types ${ }^{61-64}$ and to decrease skin carcinogenesis in mice. ${ }^{67}$

These primary remarks indicated that pomegranate seed oil is a safe and effective agent against skin cancer. ${ }^{86}$ 
Apoptosis is the most potent defense mechanism against cancer. ${ }^{91}$ Results of investigation by George et al. ${ }^{92}$ in Balb/c mice showed significant induction of apoptosis by pomegranate extract. Percent increase in apoptotic population in pomegranate extract was $18.72 \pm 1.43$.

\section{Anti-hepatocellular carcinoma}

Hepatocellular carcinoma is a common and fatal cancer which is extremely stimulated by oxidative stress. The pomegranate peel, have hepato-protective activity. ${ }^{93}$ The effect of pomegranate extract on DENA-induced hepato cell carcinogenesis, like hepatocellular carcinoma in humans, was examined in vivo. Considerable chemo-preventive potential were reported due to decrease in the incidence, size, volume and multiplicity of the hepatic nodules. Pomegranate extract also reduced in the liver lipid peroxidation and oxidation of proteins. Bishayee et al. ${ }^{94}$ suggested and supported pomegranate administration derived agents in the treatment and prevention of hepatocellular in humans.

Nutrition of rats with pomegranate pulp provided protective potential against carbon tetra chloride toxicity. ${ }^{95}$ Investigations in rats with carbon tetra chloride toxicity induced liver damage showed pomegranate pretreatment increased or retain the free radical inhibiting activity of the hepatic enzymes catalase, superoxide, peroxidase and dismutase, and resulted in 54\% decrease of lipid per-oxidation values compared to control groups verifying the antioxidant property of the pomegranate pulp. ${ }^{96}$

Bishayee et al. ${ }^{97}$ demonstrated that pomegranate bioactive compounds apply a chemo preventive effect against diethylnitrosamine-induced rat liver carcinogenesis by inhibiting hepatic oxidative. The chemo-preventive of pomegranate possess potent against hepatic carcinoma, possibly through antioxidant signaling mechanisms without any toxic expression. Pomegranate bioactive properties inhibit cell proliferation, regulate cell cycle progression, and induce apoptosis in Sprague-Dawley rats. ${ }^{98}$

\section{Efficacy and safety of pomegranate}

Studies have shown that the pomegranate have anti-inflammatory, anti-proliferative, antioxidant and anti-tumorigenic attribute by modulating multiple signaling pathways, that offer its use as a promising chemo preventive and chemotherapeutic food. ${ }^{8}$

All parts of pomegranate such as peel, juice and oil have been shown anticancer activities including interference with tumor cell proliferation, cell cycle, and angiogenesis.

The phytochemistry actions of punica granatum components capable for the treatment and prevention of cancer, as well as other diseases where chronic inflammation is believed to play an essential etiologic role. ${ }^{99}$

Pomegranates have been used without adverse effects for centuries. ${ }^{100}$ Animal Studies of pomegranate component did not indicate any toxic effects at concentrations commonly used in traditional medicine. ${ }^{29} \mathrm{http} / /$ www.ncbi.nlm.nih.gov/pmc/articles /PMC4158581/?report=printable - ref13 Pomegranate juice, oil or extracts can be used without high risk by healthy individuals. No adverse effects on liver or renal function were observed upon pomegranate administration of up to $1420 \mathrm{mg}$ /day extract tablets in humans. ${ }^{101}$

Pomegranate extracts contain significant antioxidants; have been progressed as natural supplements in order to process an alternative suitable form for using the bioactive polyphenols. ${ }^{102}$ In
Recent study by Bassiri Jahromi et al. ${ }^{103}$ have been shown that administration of 3 various doses of pomegranate peel extract in $B A L B / c$ mice produced no toxic effects in terms of food intake, weight gain, or behavioral or biochemical factors. Biochemical studies indicated no disturbances in glucose, cholesterol, alanine aminotransferase (ALT) and aspartate aminotransferase (AST) following administration of 3 various doses of pomegranate peel extracts. P. granatum peel extract administered showed normal histopathological examinations with no inflammation at the supra therapeutic dose $(7.5 \mathrm{mg} / \mathrm{kg})$.

\section{Conclusions}

The therapeutic potential of pomegranate appears to be wide variety. So, leading to an enhance popularity as a natural compounds and functional food since centuries. The pomegranate polyphenol; punicalagin, is known to have potent anticancer activity in breast, lung, and cervical cells.

All parts of the fruit were reported to have therapeutic activity including anticancer, anti-inflammatory, anti-atherogenic, anti-diabetes, hepato protective, and antioxidant activity, etc. ${ }^{4,105-108}$ Antioxidant activity of the pomegranate components has been investigated in recent years. The current research contains excellent evidence relevant to anticancer, anti-inflammatory, anti-proliferative activities of pomegranate-derived products particularly relevance to their anticancer properties. In view of the different activities of pomegranate extracts, we believe that they are suitable further investigations as potential multiple target-oriented therapy and prevention and suppression for the wide variety of cancer and its pathological outcomes. It is hoped that the present review will provide some worthwhile clues for continues explorations of this most attractive botanical species.

\section{References}

1. Longtin R. The pomegranate: nature's power fruit? JNCI J Natl Cancer Inst 2003;95:346-8.

2. Ahangari B, Sargolzaei J. Extraction of pomegranate seed oil using subcritical propane and supercritical carbon dioxide. Theor Found Chemen En 2012;46:258-65.

3. Howell AB, D'Souza DH. The pomegranate: effects on bacteria and viruses that influence human health. Evid Based Complement Alternat Med 2013;2013:606212.

4. Lansky EP, Newman RA. Punica granatum (pomegranate) and its potential for prevention and treatment of inflammation and cancer. J Ethnopharmacol 2007;19;109:177-206.

5. Ismail T, Sestili P, Akhtar S. Pomegranate peel and fruit extracts: A review of potential anti-inflammatory and antiinfective effects. J Ethnopharmacol 2012;143:397-405.

6. Tehran: Soroush Publications 1362. Avicenna (Abue-Alisina). Cannon of Medicine (Qanon) II: 306-7.

7. Lloyd JU. Punica granatum. Chicago, IL: The Western Druggist; 1897. Available from: http://www.swsbm.com/ ManualsOther/Punica granatum-Lloyd

8. Sharma P, McClees SF, Afaq F. Pomegranate for prevention and treatment of cancer: an update. Molecules 2017;22:pii:E177.

9. Amakura Y, Okada M, Tsuji S, Tonogai Y. High-performance liquid chromatographic determination with photodiode array detection of ellagic acid in fresh and processed fruits. J Chromatogr A 2000;896:87-93. 
10. Al-Zoreky NS. Antimicrobial activity of pomegranate (Punica granatum L.) fruit peels. Int J Food Microbiol 2009; 134:244-8.

11. Ben Nasr C, Ayed N, Metche M. Quantitative determination of the polyphenolic content of pomegranate peel. Zeitschrift fur Lebensmittel-Untersuchung und-Forschung 1996;203:374-8.

12. Mertens-Talcott SU, Jilma-Stohlawetz P, Rios J, et al. Absorption, metabolism, and antioxidant effects of pomegranate (Punica granatum L.) polyphenols after ingestion of a standardized extract in healthy human volunteers. J Agric Food Chem 2006;54:8956-61.

13. Tang J, Li B, Hong S, et al. Punicalagin suppresses the proliferation and invasion of cervical cancer cells through inhibition of the $\beta$-catenin pathway. Mol Med Rep 2017;16:143944.

14. Noda Y, Kaneyuki T, Mori A, Packer L. Antioxidant activities of pomegranate fruit extract and its anthocyanidins: delphinidin, cyanidin, and pelargonidin. J Agric Food Chem 2002;50: 166-71.

15. Van Elswijk DA, Schobel UP, Lansky EP, et al. Rapid dereplication of estrogenic compounds in pomegranate (Punica granatum) using on-line biochemical detection coupled to mass spectrometry. Phytochemistry 2004;65:233-41.

16. Ozbay T, Nahta R. Delphinidin inhibits HER 2 and Erk1/2 signaling and suppresses growth of HER2-overexpressing and triple negative breast cancer cell lines. Breast Cancer (Auckl) 2011;5:143-54.

17. Murthy CKN, Vittal K, Reddy VK, et al. Study on wound healing activity of Punica granatum peel. J Med Food 2004; 7:256-9.

18. Middha SK, Usha T, Pande V. HPLC evaluation of phenolic profile, nutritive content, and antioxidant capacity of extracts obtained from Punica granatum fruit peel. Adv Pharmacol Sci 2013:296236.

19. Afaq F, Mukhtar H. Botanical antioxidants in the prevention of photocarcinogenesis and photoaging. Exp Dermatol 2006;15:678-84.

20. Akbarpour V, Hemmati K, Sharifani M. Physical and chemical properties of pomegranate (Punica granatum L.) fruit in maturation stage. Am-Euras J Agric Environ Sci 2009;6:4116.

21. Adhami VM, Khan N, Mukhtar H. Cancer chemoprevention by pomegranate: laboratory and clinical evidence. Nutr Cancer 2009;61:811-5.

22. Lall RK, Syed DN, Adhami VM, et al. Dietary polyphenols in prevention and treatment of prostate cancer. Int J Mol Sci 2015;16:3350-76.

23. Menezes SM, Cordeiro LN, Viana GS. Punica granatum (pomegranate) extract is active against dental plaque. J Herb Pharmacother 2006;6:79-92.

24. Abdollahzdeh SH, Mashouf $\mathrm{R}$, Mortazavi $\mathrm{H}$, et al. Antibacterial and antifungal activities of Punica granatum peel extracts against oral pathogens. J Dent (Tehran) 2011;8:1-6.

25. Anibal PC, Peixoto IT, Foglio MA, Höfling JF. Antifungal activity of the ethanolic extracts of Punica granatum L. and evaluation of the morphological and structural modifications of its compounds upon the cells of Candida spp. Braz J Microbiol 2013;44:839-48.

26. Bassiri-Jahromi S, Katiraee F, Hajimahmoodi M, et al. In vitro antifungal activity of various Persian cultivars of Punica granatum L. extracts against Candida species. Jundishapur J Nat Pharm Prod 2015;10:e19754.
27. Bassiri Jahromi S, Pourshafie MR, Mirabzadeh E, et al. In vivo comparative evaluation of pomegranate (Punica granatum) peel extract as alternative agents for nystatin against oral candidiasis. Iran J Med Sci 2017 [In press].

28. Reddy BU, Mullick R, Kumar A, et al. Small molecule inhibitors of HCV replication from Pomegranate. Sci Rep 2014;4:5411.

29. Mohan M, Patankar P, Ghadi P, Kasture S. Cardioprotective potential of Punica granatum extract in isoproterenol-induced myocardial infarction in Wistar rats. J Pharmacol Pharmacother 2010;1:32-7.

30. Middha SK, Bhattacharjee B, Saini D, et al. Protective role of Trigonella foenum graceum extract against oxidative stress in hyperglycemic rats. Eur Rev Med Pharmacol Sci 2011;15:427-35.

31. Tavassoli-Hojjati S, Aliasghar E, Ahmadian Babaki F, et al. Pomegranate juice (Punica granatum): a new storage medium for avulsed teeth. J Dent (Tehran) 2014;11:225-32.

32. Bhadbhade SJ, Acharya AB, Rodrigues SV, Thakur SL. The antiplaque efficacy of pomegranate mouthrinse. Quintessence Int 2011;42:29-36.

33. Pacheco-Palencia LA, Noratto G, Hingorani L, et al. Protective effects of standardized pomegranate (Punica granatum L.) polyphenolic extract in ultraviolet-irradiated human skin fibroblasts. J Agric Food Chem 2008;56:843441.

34. Subash S, Essa MM, Al-Asmi A, et al. Tradit. Pomegranate from Oman alleviates the brain oxidative damage in transgenic mouse model of Alzheimer's disease. Complement Med 2014;4:232-8.

35. West T, Atzeva M, Holtzman DM. Pomegranate polyphenols and resveratrol protect the neonatal brain against hypoxicischemic injury. Dev Neurosci 2007;29:363-72.

36. Ahmed MA, El Morsy EM, Ahmed AA. Pomegranate extract protects against cerebral ischemia/reperfusion injury and preserves brain DNA integrity in rats. Life Sci 2014;110:61-9.

37. Rasheed Z, Akhtar N, Haqqi TM. Pomegranate extract inhibits the interleukin-1 $\beta$-induced activation of MKK-3, p38 $\alpha$-MAPK and transcription factor RUNX-2 in human osteoarthritis chondrocytes. Arthritis Res Ther 2010;12: R195.

38. Mo J, Panichayupakaranant P, Kaewnopparat N, et al. Wound healing activities of standardized pomegranate rind extract and its major antioxidant ellagic acid in rat dermal wounds. $\mathrm{J}$ Nat Med 2014;68:377-86.

39. Sadeghipour A, Eidi M, Ilchizadeh Kavgani A, et al. Lipid lowering effect of Punica granatum L. peel in high lipid diet fed male rats. Evid Based Complement Alternat Med 2014;2014:432650.

40. Dell'agli M, Galli GV, Bulgari M, et al. Ellagitannins of the fruit rind of pomegranate (Punica granatum) antagonize in vitro the host inflammatory response mechanisms involved in the onset of malaria. Malar J 2010;9:208.

41. Malik A, Mukhtar H. Prostate cancer prevention through pomegranate fruit. Cell Cycle 2006;5:371-3.

42. Malik A, Afaq F, Sarfaraz S, et al. Pomegranate fruit juice for chemoprevention and chemotherapy of prostate cancer. Proc Natl Acad Sci U S A 2005;102:14813-8.

43. Al-Jarallah A, Igdoura F, Zhang Y, et al. The effect of pomegranate extract on coronary artery atherosclerosis in SRBI/APOE double knockout mice. Atherosclerosis 2013;228:80-9.

44. Mohan M, Waghulde H, Kasture S. Effect of pomegranate juice on Angiotensin II-induced hypertension in diabetic 
Wistar rats. Phytother Res 2010;Suppl 2:S196-203.

45. Sen S, Chakraborty R, Sridhar C, et al. Free radicals, antioxidants, diseases and phytomedicines: current status and future prospect. Int J Pharm Sci Rev Res 2010;3:91.

46. Syed DN, Chamcheu JC, Adhami VM, Mukhtar H. Pomegranate extracts and cancer prevention: molecular and cellular activities. Anticancer Agents Med Chem 2013;13: 1149-61.

47. Singh R, Singh MK, Chandra LR, et al. In vitro antioxidant and free radical scavenging activity of Macrotyloma uniflorum (Gahat dal) from Kumauni region. J Fundam Appl Sci 2012;1:7-10.

48. Li Y, Guo C, Yang J, et al. Evaluation of antioxidant properties of pomegranate peel extract in comparison with pomegranate pulp extract. Food Chem 2006;96:254-60.

49. Kaneyuki T, Noda Y, Traber MG, et al. Superoxide Anion and Hydroxy Radical Scavenging activities of vegetable extracts measured usind electron spine resonance. Biochem Mol Biol Int 1999;47:979-89.

50. Schubert A, Pereira DF, Zanin FF, et al. Comparison of antioxidant activities and total polyphenolic and methylxanthine contents between the unripe fruit and leaves of Ilex paraguariensis A. St Hil Pharmazie 2007;62:876-80.

51. Gil MI, Tomas-Barberan FA, Hess-Pierce B, et al. Antioxidant activity of pomegranate juice and its relationship with phenolic composition and processing. J Agric Food Chem 2000;48:4581-9.

52. Aviram M, Fuhrman B. Polyphenolic flavonoids inhibit macrophage-mediated oxidation of LDL and attenuate atherogenesis. Atherosclerosis 1998;137 Suppl:S45-50.

53. Murthy KNC, Jayaprakasha GK, Singh RP. Studies on antioxidant activity of pomegranate (Punica granatum) peel extract using in vivo models. J Agric Food Chem 2002;50:4791-5.

54. Moneim AEA. Antioxidant activities of Punica granatum (pomegranate) peel extract on brain of rats. J Med Plant Res 2012;6:195-9.

55. Chidambara Murthy KN, Jayaprakasha GK, Singh RP. Studies on antioxidant activity of pomegranate (Punica granatum) peel extract using in vivo models. J Agric Food Chem 2002;50:4791-5.

56. Jurenka JS. Therapeutic applications of pomegranate (Punica granatum L.): a review. Altern Med Rev 2008;13:128-44.

57. Yang CS, Landau JM, Huang MT, Newmark HL. Inhibition of carcinogenesis by dietary polyphenolic compounds. Ann Rev Nutr 2001;21:381-406.

58. Quirynen M, Teughels W, Haake SK, Newman MG. Microbiology of periodontal diseases. In: Giannobile WV, editor. Carranza's clinical periodontology. 10th ed. Missouri: WB Saunders Company; 2006. pp 134-69.

59. Mehta VV, Rajesh G, Rao A, et al. Antimicrobial efficacy of Punica granatum mesocarp, Nelumbo nucifera Leaf, Psidium guajava Leaf and Coffea Canephora extract on common oral pathogens: an in vitro study. J Clin Diagn Res 2014;8:ZC658.

60. Dahlawi H, Jordan-Mahy N, Clench M, et al. Polyphenols are responsible for the proapoptotic properties of pomegranate juice on leukemia cell lines. Food Sci Nutr 2013;1:196-208.

61. Kim ND, Mehta R, Yu W, et al. Chemoprevetive and adjuvant therapeutic potential of pomegranate (Punica granatum) for human breast cancer. Breast Cancer Res Treat 2002; 71:203-17.

62. Albrecht M, Jiang W, Kumi-Diaka J, et al. Pomegranate extracts potently suppress proliferation, xenograft growth, and invasion of human prostate cancer cells. J Med Food 2004;7:274-83.

63. Kawaii S, Lansky EP. Differentiation-promoting activity of pomegranate (Punica granatum) fruit extracts in HL-60 human promyelocytic leukemia cells. J Med Food 2004;7:138.

64. Lansky EP, Jiang W, Mo H, et al. Possible synergistic prostate cancer suppression by anatomically discrete pomegranate fractions. Invest New Drugs 2005;23:11-20.

65. Hora JJ, Maydew ER, Lansky EP, Dwivedi C. Chemopreventive effects of pomegranate seed oil on skin tumor development in CD1 mice. J Med Food 2003;6:15761.

66. Mehta R, Lansky EP. Breast cancer chemopreventive properties of pomegranate (Punica granatum) fruit extracts in a mouse mammary organ culture. Eur J Cancer Prev 2004; 13:345-8.

67. Viuda-Martos M, Fernandez-Lopez J, Perez Alvarez JA. Pomegranate and its many functional components as related to human health: a review. Compr Rev Food Sci Food Saf 2010;10:635-54.

68. Settheetham W, Ishida T. Study of genotoxic effects of antidiarrheal medicinal herbs on human cells in vitro. Southeast Asian J Trop Med Public Health 1995;1:306-10.

69. Mavlyanov SM, Islambekov SY, Karimdzhanov AK, Ismailov AI. Polyphenols of pomegranate peels show marked anti-tumor and anti-viral action. Chem Nat Compounds 1997;33:98-9.

70. Adams LS, Seeram NP, Aggarwal BB, et al. Pomegranate juice, total pomegranate ellagitannins, and punicalagin suppress inflammatory cell signaling in colon cancer cells. J Agric Food Chem 2006;54:980-5.

71. Naiki-Ito A, Chewonarin T, Tang M, et al. Ellagic acid, a component of pomegranate fruit juice, suppresses androgendependent prostate carcinogenesis via induction of apoptosis. Prostate 2015;75:151-60.

72. Larrosa M, Tomas-Barberan FA, Espin JC. The dietary hydrolysable tannin punicalagin releases ellagic acid that induces apoptosis in human colon adenocarcinoma Caco-2 cells by using the mitochondrial pathway. J Nutr Biochem 2006; 17:611-25.

73. Seeram NP, Adams LS, Henning SM, et al. In vitro anti-proliferative, apoptotic and antioxidant activities of punicalagin, ellagic acid and a total pomegranate tannin extract are enhanced in combination with other polyphenols as found in pomegranate juice. J Nutr Biochem 2005;16:360-7.

74. Shirode AB, Bharali DJ, Nallanthighal $S$, et al. Nanoencapsulation of pomegranate bioactive compounds for breast cancer chemoprevention. Int $\mathrm{J}$ Nanomedicine 2015;10:475-84.

75. Jeune MA, Kumi-Diaka J, Brown J. Anticancer activities of pomegranate extracts and genistein in human breast cancer cells. J Med Food 2005;8:469-75.

76. Pantuck AJ, Pettaway CA, Dreicer R, et al. A randomized, double-blind, placebo-controlled study of the effects of pomegranate extract on rising PSA levels in men following primary therapy for prostate cancer. Prostate Cancer Prostatic Dis 2015;18:242-8.

77. Khan N, Hadi N, Afaq F, Syed D N, Kweon MH, Mukhtar H. Pomegranate fruit extract inhibits prosurvival pathways in human A549 lung carcinoma cells and tumor growth in athymic nude mice. Carcinogenesis 2007;28:163-73.

78. Khan N, Afaq F, Kweon MH, et al. Oral consumption of pomegranate fruit extract inhibits growth and progression of 
primary lung tumors in mice. Cancer Res 2007;67:3475-82.

79. Li Y, Yang F, Zheng W, et al. Punica granatum (pomegranate) leaves extract induces apoptosis through mitochondrial intrinsic pathway and inhibits migration and invasion in nonsmall cell lung cancer in vitro. Biomed Pharmacother 2016;80:227-35.

80. Khan N, Afaq F, Mukhtar H. Cancer chemoprevention through dietary antioxidants: progress and promise. Antioxid Redox Signal 2008;10:475-510.

81. Dana N, Haghjooy Javanmard S, Rafiee L. Role of peroxisome proliferator-activated receptor alpha and gamma in antiangiogenic effect of pomegranate peel extract. Ran J Basic Med Sci 2016;19:106-10.

82. Larrosa M, González-Sarrías A, Yáñez-Gascón MJ, et al. Anti-inflammatory properties of a pomegranate extract and its metabolite urolithin-A in a colitis rat model and the effect of colon inflammation on phenolic metabolism. J Nutr Biochem 2010;21:717-25.

83. Kohno H, Suzuki R, Yasui Y, et al. Pomegranate seed oil rich in conjugated linolenic acid suppresses chemically induced colon carcinogenesis in rats. Cancer Sci 2004;95:481-6.

84. Li H, Wang Z, Liu Y. Review in the studies on tannins activity of cancer prevention and anticancer. Zhong Yao Cai 2003;26:444-8.

85. Miyamoto K, Nomura M, Sasakura M, et al. Antitumor activity of oenothein B, a unique macrocyclic ellagitannin. Jpn J Cancer Res 1993;84:99-103.

86. Hora JJ, Maydew ER, Lansky EP, Dwivedi C. Chemopreventive effects of pomegranate seed oil on skin tumor development in CD1 mice. J Med Food 2003;6:15761.

87. Afaq F, Saleem M, Krueger CG, et al. Anthocyanin and hydrolyzable tannin-rich pomegranate fruit extract modulates MAPK and NF-kappaB pathways and inhibits skin tumorigenesis in CD-1 mice. Int J Cancer 2005;113:423-33.

88. Afaq F, Malik A, Syed D, et al. Pomegranate fruit extract modulates UV-B-mediated phosphorylation of mitogen-activated protein kinases and activation of nuclear factor kappa B in normal human epidermal keratinocytes paragraph sign. Photochem Photobiol 2005;81:38-45.

89. Pacheco-Palencia LA, Noratto G, Hingorani L, et al. Protective effects of standardized pomegranate (Punica granatum L.) polyphenolic extract in ultraviolet-irradiated human skin fibroblasts. J Agric Food Chem 2008;56:8434-41.

90. Syed DN, Malik A, Hadi N, et al. Photochemopreventive effect of pomegranate fruit extract on UVA-mediated activation of cellular pathways in normal human epidermal keratinocytes. Photochem Photobiol 2006;82:398-405.

91. Lowe SW, Lin AW. Apoptosis in cancer. Carcinogenesis 2000;21:485-95.

92. George J, Singh M, Srivastava AK, et al. Synergistic growth inhibition of mouse skin tumors by pomegranate fruit extract and diallyl sulfide: evidence for inhibition of activated MAPKs/NF- $\kappa$ B and reduced cell proliferation. Food Chem Toxicol 2011;49:1511-20.

93. Bhatia D, Thoppil RJ, Mandal A, et al. Pomegranate bioactive constituents suppress cell proliferation and induce apoptosis in an experimental model of hepatocellular carcinoma: role of Wnt/ $\beta$-catenin signaling pathway. Evid Based Complement Alternat Med 2013;2013:371813.

94. Bishayee A, Bhatia D, Thoppil RJ, et al. Pomegranate-mediated chemoprevention of experimental hepatocarcinogenesis involves Nrf2-regulated antioxidant mechanisms. Carcinogenesis 2011;32:888-96.

95. Al-Olayan EM, El-Khadragy MF, Metwally DM, Abdel Moneim AE. Protective effects of pomegranate (Punica granatum) juice on testes against carbon tetrachloride intoxication in rats. BMC Complement Altern Med 2014;14:164.

96. Bishayee A, Dhir N. Resveratrol-mediated chemoprevention of diethyl-nitrosamine-initiated hepatocarcinogenesis: inhibition of cell proliferation and induction of apoptosis. ChemBiol Interact 2009;79:131-44.

97. Bishayee A, Mbimba T, Thoppil RJ, et al. Anthocyanin-rich black currant (Ribes nigrum L.) extract affords chemoprevention against diethyl-nitrosamine induced hepatocellular carcinogenesis in rats. J Nutr. Biochem 2011;22:1035-46.

98. Kaplan M, Hayek T, Raz A, et al. Pomegranate juice supplementation to atherosclerotic mice reduces macrophage lipid peroxidation, cellular cholesterol accumulation and development of atherosclerosis. J Nutr 2001;131:2082-9.

99. Syed DN, Chamcheu J-C, Adhami VM, Mukhtar H. Pomegranate extracts and cancer prevention: molecular and cellular activities. Anticancer Agents Med Chem 2013; 13:1149-61.

100. Wang L, Martins-Green M. Pomegranate and its components as alternative treatment for prostate cancer. Int $\mathrm{J}$ Mol Sci $2014 ; 15 ; 2014$

101. Viladomiu M, Hontecillas R, Lu P, Bassaganya-Riera J. Preventive and prophylactic mechanisms of action of pomegranate bioactive constituents. Evid Based Complement Alternat Med 2013;2013:789764.

102. Heber D, Seeram NP, Wyatt H, et al. Safety and antioxidant activity of a pomegranate ellagitannin-enriched polyphenol dietary supplement in overweight individuals with increased waist size. J Agric Food Chem 2007;28;55:10050-4.

103. Bassiri Jahromi S, Pourshafie MR, Mirabzadeh E, et al. Punica granatum peel extract toxicity in mice. Jundishapur J Nat Pharm Prod 2015; 10:e23770.

104. Katz SR, Newman RA, Lansky EP. Punica granatum: heuristic treatment for diabetes mellitus. J Med Food 2007;10:2137.

105. Naz S, Siddiqi R, Ahmad S, et al. Antibacterial activity directed isolation of compounds from Punica granatum. J Food Sci 2007;72:M341-5.

106. Rout S, Banerjee R. Free radical scavenging, anti-glycation and tyrosinase inhibition properties of a polysaccharide fraction isolated from the rind from Punica granatum. Bioresour Technol 2007;98:3159-63.

107. Wang R, Ding Y, Liu R, et al. Pomegranate: constituents, bioactivities and pharmacokinetics. Fruit Veg Cereal Sci 2010;2:77-87.

108. Colombo E, Sangiovanni E, Dell'Agli AM. Review on the anti-inflammatory activity of Pomegranate in the gastrointestinal tract. Evid-Based Complement Alternat Med 2013; 2013:247145. 